\title{
Borrifar inseticidas de efeito residual para mitigar o risco da microcefalia causada pela zika
}

\section{| ${ }^{1}$ Eduardo Dias Wermelinger |}

\author{
${ }^{1}$ Ciências Biológicas, Fundação Oswaldo Cruz. Rio de Janeiro-RJ, Brasil (edw@fiocruz.br). ORCID: 0000-0003-1926-4789. \\ Recebido em: 11/02/2018 \\ Revisado em: 08/05/2018 \\ Aprovado em: 22/06/2018 \\ DOI: http://dx.doi.org/10.1590/\$0103-73312018280303
}

No Brasil, entre as semanas epidemiológicas 01 e 52/2017 (30/12/2017), foram confirmados 542 casos de alteraçóes no crescimento e desenvolvimento em bebês e crianças relacionadas ao vírus zika e outras etiologias infecciosas, com destaque para as microcefalias. Desse total, em $45,6 \%$ se reportou algum tipo de cuidado: puericultura, estimulação precoce e atenção especializada; no entanto, receberam os três tipos de serviços apenas 13,82\% (75 casos) (BRASIL, 2018). Esse cenário ilustra, de forma breve, a atual relevância da disseminação do vírus zika para a saúde pública brasileira.

$\mathrm{Na}$ ausência de vacina, a profilaxia da zika depende do controle eficaz dos mosquitos vetores, em particular, o Aedes aegypti. Entretanto, as ações de controle nos grandes centros urbanos brasileiros não têm conseguido alcançar a eficácia necessária para barrar a disseminação dos vírus da dengue, chikungunya e zika, devido, sobretudo, a complexos determinantes sociais e ambientais. Adicionalmente, a possibilidade de haver outras espécies de mosquitos urbanos capazes de transmitir o vírus zika (AYRES, 2016; GUEDES et al., 2017) aumentaria as dificuldades dos serviços de controle de seus vetores.

Assim, na ausência de vacinas e de açóes eficazes para o controle dos mosquitos vetores em termos profiláticos, é importante propor açôes específicas capazes de mitigar o risco das grávidas se infectarem com o vírus em situaçóes de surtos epidêmicos. 
Entre as propostas para promover melhoras no controle do $A$. aegypti, está a borrifação de inseticidas de efeito residual no interior das residências ou indoor residual spraying (IRS) (BRASIL, 2016; WHO, 2016), técnica usual na profilaxia da malária, doença de Chagas e leishmaniose. De fato, estudos demonstraram a eficácia da IRS no combate ao $A$. aegypti (CHADEE, 2013; PAREDES-ESQUIVEL et al., 2016), mas não são apontadas medidas antivetoriais específicas para proteger as grávidas de se infectarem com o vírus zika. Nesse contexto, a técnica da IRS poderá ser especialmente útil para mitigar o risco de novos casos de microcefalia causado pelo vírus zika, sobretudo em países que não possuem serviços eficazes de controle de vetores.

\section{IRS para mitigar o risco de microcefalia}

Apesar da eficácia histórica da IRS no controle de mosquitos vetores, não é factível nem recomendável disseminar esse técnica em vastas áreas urbanas, sob risco de agravar ainda mais o problema da resistência dos mosquitos vetores urbanos aos inseticidas. No entanto, a técnica da IRS pode conferir conveniente proteção pontual, local e temporária para as grávidas e mitigar o risco de surgirem novos casos de microcefalia causados pelo zika vírus. Mulheres que vivem ou trabalhem em áreas onde há a circulação do vírus zika e onde os serviços de controle do $A$. aegypti não são eficientes, ao engravidarem poderiam receber imediata e eficaz proteção do ataque dos mosquitos se suas casas e locais de trabalho fossem borrifados com inseticidas de ação residual nas paredes internas, sem prejuízo das tradicionais recomendaçóes de controle dos criadouros intra e periodomicílio. Dessa forma, as grávidas contariam com uma proteção temporária adicional até o parto, facilitada pelo característico poder residual dos inseticidas utilizados no IRS. A intervenção é factível porque os procedimentos, inseticidas e formulações são conhecidos (WHO, 2007; 2015), assim como a segurança para as grávidas (WHO, 2011).

\section{O manejo da resistência}

O histórico de utilização dos inseticidas, muitas vezes exagerado, permitiu o surgimento de populaçôes de $A$. aegypti resistentes no Brasil (CUNHA et al., 2005; MONTELLA et al., 2007; MACIEL-DE-FREITAS et al., 2014), oferecendo sério obstáculo à eficácia desses biocidas. Existem, no entanto, técnicas de manejo da 
resistência que podem ajudar a contornar esse obstáculo. Idealmente, para assegurar eficácia às borrifaçôes, é importante que tais açōes sejam orientadas com as técnicas de manejo da resistência, elaboradas principalmente para a malária, realizando bioensaios prévios para detectar a resistência ou susceptibilidade das populaçôes locais de $A$. aegypti aos inseticidas e promover, se necessário, a rotação de inseticidas (WHO, 2011a; 2012). Em analogia, do mesmo modo como hoje tem sido cada vez mais rotineiro realizar testes antimicrobianos para prescrever antibióticos no combate às bactérias resistentes, torna-se também necessário realizar testes sobre a susceptibilidade das populaçóes locais de $A$. aegypti aos diferentes inseticidas antes de utilizar a técnica da ISR ou outra qualquer para o controle químico.

\section{A vigilância epidemiológica}

Para utilizar técnicas de IRS visando mitigar os casos de microcefalia, é importante que os serviços de controle de vetores estejam permanentemente informados dos serviços de vigilância epidemiológica, em particular, da vigilância virológica. As mulheres residentes, ou que trabalhem em áreas onde há circulação do vírus zika, logo que tiverem confirmação da gravidez devem ser orientadas a notificar os serviços de vigilância que, por sua vez, devem comunicar os serviços de controle de vetores para borrifar as residências ou locais de trabalho dessas grávidas.

\section{A comunicação como estratégia}

É recomendável que a população seja informada da utilidade e importância estratégica dessa técnica para mitigar o risco de microcefalia. Assim, futuros pais e mães, imediatamente após confirmação da gravidez, devem ser orientados a informar e solicitar a borrifação de inseticidas de efeito residual nas casas e locais de trabalho das grávidas, caso estejam em áreas onde haja circulação do vírus zika identificados pelos serviços de vigilância epidemiológica.

\section{Considerações finais}

É importante enfatizar, entretanto, que a utilização dos inseticidas, embora útil e necessária, é um paliativo cuja eficácia é temporária e que, principalmente, não resolve os problemas ambientais responsáveis pela proliferação dos vetores. Assim, a possível utilização da técnica da IRS não atenua os esforços na busca de um 
controle eficaz do $A$. aegypti capaz de bloquear a transmissão dos vírus e alcançar resultados profiláticos efetivos.

Nesse sentido, devem-se aprimorar as açóes de controle do $A$. aegypti nas cidades brasileiras, sobretudo priorizando a eliminação duradoura e sustentável dos criadouros urbanos dentro de uma estratégia de controle integrado.

\section{Referências}

AYRES, C. F. J. Identification of Zika vírus vectors and implications for control. The Lancet Infectious Diseases, v. 6, n. 3, p. 278-279, 2016. https://doi.org/10.1016/S1473-3099(16)00073-6 BRASIL. Ministério da Saúde. Relatório da Reunião Internacional para Implementação de Alternativas para o controle do Aedes aegypti no Brasil. Boletim Epidemiológico, v. 47, n. 15, p. 1-9, 2016. Disponível em: <http://portalarquivos.saude.gov.br/images/pdf/2016/abril/05/2016012---Relatorio-reuniao-especialistas-Aedes-publica----o.pdf>.

BRASIL. Ministério da Saúde. Monitoramento integrado de alteraçóes no crescimento e desenvolvimento relacionadas à infecção pelo vírus zika e outras etiologias infecciosas, até a Semana Epidemiológica 52/2017. Boletim Epidemiológico, v 49, n. 6, p. 1-10, 2018. Disponível em: <http://portalarquivos2.saude.gov.br/images/pdf/2018/fevereiro/20/2018-003-Final.pdf>.

CHADEE, D. D. Resting behaviour of Aedes aegypti in Trinidad: with evidence for the reintroduction of indoor residual spraying (IRS) for dengue control. Parasites \& Vectors, v. 6, p. 255, 2013. https://doi.org/10.1186/1756-3305-6-255

CUNHA, M. P. et al. Monitoring of resistance to the pyrethroidcypermethrin in Brazilian Aedes aegypti (Diptera: Culicidae) populations collected between 2001 and 2003. Memórias do Instituto Oswaldo Curz, v. 100, n. 4, p. 441-444, 2005.

GUEDES, D. R. D. et al. Zika vírus replication in the mosquito Culex quinquefasciatus in Brazil. Emerging Microbes \& Infections, v. 6, n. 8, p. e69, 2017. doi:10.1038/emi.2017.59

MACIEL-DE-FREITAS, R. et al. Plos One, v. 9, n. 3, p. e92424, 2014. https://doi.org/10.1371/ journal.pone.0092424

MONTELLA, I. R. et al. Insecticide Resistance Mechanisms of Brazilian Aedes aegypti Populations from 2001 to 2004. The American Journal of Tropical Medicine and Hygiene, v. 77, n. 3, p. 467-477, 2007. Disponível em: <https://www.ncbi.nlm.nih.gov/pubmed/17827362>.

PAREDES-ESQUIVEL, C. et al. The impact of indoor residual spraying of deltamethrin on dengue vector populations in the Peruvian Amazon. Acta Tropica, v. 154, p. 139-144, 2016. doi: 10.1016/j.actatropica.2015.10.020. 
WORLD HEALTH ORGANIZATION. Generic risk assessment model for indoor residual spraying of insecticides. Geneva: WHO, 2011. Disponível em: http://apps.who.int/iris/ bitstream/10665/44676/1/9789241502177_eng.pdf.

- Global plan for insecticide resistance management in malaria vectors. Geneva: WHO Global Malaria Programme 2012. Disponível em: http://apps.who.int/iris/ bitstream/10665/44846/1/9789241564472_eng.pdf.

Indoor Residual Spraying. An operational manual for indoor residual spraying (IRS) for malaria transmission control and elimination. $2^{\text {nd }}$ ed. Geneva: WHO, 2015. Disponível em: http://apps.who.int/iris/bitstream/10665/177242/1/9789241508940_eng.pdf.

. Manual for Indoor Residual Spraying - Application of Residual Sprays for Vector Control.

Geneva: WHO, 2007. Disponível em: http://apps.who.int/iris/bitstream/10665/69664/1/ WHO_CDS_NTD_WHOPES_GCDPP_2007.3_eng.pdf .

. The technical basis for coordinated action against insecticide resistance: preventing the effectiveness of modern malaria vector control. Geneva: WHO Global Malaria Programme, 2011a. Disponível em: http://apps.who.int/iris/bitstream/10665/44526/1/9789241501095_eng.pdf.

. Vector control operations framework for zika virus. Geneva: WHO, 2016. Disponível em: http://www.who.int/csr/resources/publications/zika/vector-control/en/. 